\title{
TEOLOGIE EN RENAISSANCE
}

\author{
J.H. van Wyk \\ Hammanskraalse Teologiese Skool \\ Potchefstroomse Universiteit vir Christelike Hoër Onderwys
}

\begin{abstract}
In this article some theological perspectives of the Renaissance period are highlighted and discussed. The conclusion arrived at is that we can hardly speak of a "theology of the Renaissance", and that much of the observations about and criticism of the Renaissance period consist of generalisations. Although the author has reservations conceming Renaissance thought in general appreciation for cerrain facets is stated.
\end{abstract}

\section{INLEIDING}

Die probleem waarvoor 'n navorser oor die Renaissance te staan kom, is nie alleen dié van die (on-)toeganklikheid van bronne nie, maar ook dat daar ' $n$ wye reeks van soms botsende interpretasies oor die Renaissance bestaan. Die gevaar van veralgemening is ook lewensgroot, die gevaar naamlik om nie - soos die Renaissance so uitdruklik geleer het - na die bronne (ad fonles!) terug te keer nie.

Wat hier aangebied word, maak nie aanspraak op volledigheid en finaliteit nie. Dit is 'n voorlopige momentopname van ' $n$ ryk geskakeerde en genuanseerde periode in die kultuurgeskiedenis van die mensheid.

Soos bekend is die woord Renaissance afgelei van die Franse woord renaitre wat beteken herbore word. Dit is 'n dinamiese kultuurbeweging wat in Italië begin het en weldra oor Europa versprei het en gekenmerk was deur ' $n$ algehele vernuwing op geestelike, maatskaplike en akademiese gebied. Daar is navorsers wat van oordeel is dat die Renaissance ongeveer van 1350 tot 1600 gestrek het, maar in hierdie artikel sal hoofsaaklik op die 14e en 15e eeu gekonsentreer word, wel te verstaan dat die Renaissance 'n duidelike aanloop en afloop gehad het.

Die Renaissance was ' $n$ tyd van opwinding en ontdekking en horisonverbreding. Gedurende die $14 \mathrm{e}$ en $15 \mathrm{e}$ eeu is die kompas ontdek, buskruit gemaak, 'n bril ontwerp, manuskripte van ou bronne is gevind, Plato, Aristoteles en die Stoa is bestudeer, die Nuwe Testament is in Grieks vertaal, universiteite het ontspring. Groot invloed is uitgeoefen deur die ontwikkeling van die boekdrukkuns rondom 1450 en die ont- 
dekking van Amerika deur Columbus in 1492 . Hierdie ontdekking van nuwe wêrelde het gepaard gegaan met 'n selfontdekking van die mens.

Dit was ook die tyd van groot kulturele ontwaking, die tyd van die groot skilders soos Giotto (1266-1336), Leonardo da Vinci (1452-1519), Michelangelo (1475-1564) en Raphael (1483-1520); die groot digters soos Dante (1265-1321) en Petrarca (13041374); die groot argitekte soos onder andere Bramante (1444-1514); die opkoms van die regswetenskap, Machiavelli (1469-1527); en die ontwikkeling van die natuurwetenskap deur Copernicus (1473-1543) en Galilei (1564-1642). Dit is opvallend dat hierdie periode geen werklike groot filosoof of teoloog opgelewer het nie, tensy ons Desiderius Erasmus (1467-1536) as 'n "teoloog" wil beskou - want 'n groot geleerde was hy inderdaad. Juis daarom is dit so moeilik om 'n tema soos die teologie van die Renaissance te behandel omdat daar nie, soos in die Middeleeue byvoorbeeld, 'n Thomas Aquinas was nie.

In bronne word verskillende uiteenlopende tiperinge van die Renaissance gevind, iets wat die gevaar van misduiding baie vergroot. So word daar byvoorbeeld daarop gewys (vgl. Sassen, 1946:33; Klapwijk, 1986:7-14) dat die Renaissance gekenmerk word deur

- 'n intense belangstelling in die natuur en wêreldse werklikheid, teenoor die geestelike en kerklike werklikheid (naturalisme/sekularisme);

- 'n verering van die mens, die lewe, die krag, asook 'n konsentrasie op die vermoëns van die mens (humanisme);

* 'n matelose verlange na kennis en 'n vertroue op die menslike verstand (rasionalisme);

- 'n hewige verlange na die volledige verwerkliking van lewensmoontlikhede en die menslike persoonlikheid (optimisme);

* 'n emansipasie van die gesag van die openbaring van God in die Skrif (outonomisme);

* 'n konsentrasie op die individu wat hom losmaak van die Middelecuse kerklike en sosiale bindinge (individualisme);

- 'n konsentrasie op die konkrete, die werklikheid, en nie op abstrakte probleemstellings nie (anti-metafisies).

Ofskoon sulke algemene tiperings wel waarheidsmomente bevat, is dit tog te veralgemenend en te ongenuanseerd om heeltemal waar te wees. Dit is eenvoudig té ongenuanseerd om die lewensbeskouing van die Renaissance as suiwer optimisties, antroposentries en kosmosentries te omskryf.

In sy waardevolle studie oor die religieuse problematiek van die Renaissance bied Rienstra (1981) 'n uitstekende oorsig oor die huidige stand van navorsing. Hy wys 
daarop dat die tradisionele siening van Jacob Burckhardt uit die vorige eeu (1860), naamlik dat die Renaissance-humanisme in wese paganisties en anti-Christelik was, in die lig van die jongste navorsing, veral dié van Trinkhaus, Kristeller en Oberman, onhoudbaar is.

Aangesien daar kwalik sprake kan wees van 'n teologie van die Renaissance, word vervolgens enkele belangrike teologiese temas uit hierdie periode nader toegelig en van evaluerende opmerkings voorsien.

\section{TEOLOGIESE TEMAS}

\section{$2.1 \quad$ God en mens}

Die eerste tema waaraan ons aandag gee, handel oor die verhouding van God en mens. Daarmee staan ons tewens in die hart van die Renaissance-denke, wat gewoonlik as humanisme getipeer word. Die vraag ontstaan egter of dit in die humanisme van die Renaissance werklik gegaan het oor 'n vergoddeliking van die mens (en 'n vermensliking van God), oor 'n outokrasie ten koste van 'n teokrasie, 'n outonomie ten koste van 'n teonomie, 'n antroposentrisme ten koste van teosentrisme.

Kristeller (1979:67-81), wat 'n besondere studie van die Renaissance gemaak het, wys daarop dat die Renaissance nie (meer) as 'n paganistiese (ateistiese of panteistiese) beweging afgemaak kan word nie. Die humaniste het byvoorbeeld die leerstellings van die Christendom aanvaar en was lidmate van die kerk. Wél is dit waar dat daar 'n definitiewe groei was in die rigting van nie-religieuse, intellektuele belange en inderdaad het die humanisme die teologie en godsdiens beïnvloed in soverre dit 'n aanval was, nié op die teologie as sodanig nie, maar op die teologiese skolastiek (=logisisme en sistematisme) en 'n studie van die oorspronklike (Hebreeuse en Griekse) bronne genoodsaak het.

Van deurslaggewende betekenis is in hierdie verband die definisie wat van die konsep humanisme gegee word. Moet daaronder 'n humanisme verstaan word soos wat dit in die 19e-eeuse (ateïstiese) Marxisme en in die 20e-eeuse eksistensialisme vorm aangeneem het? Inderdaad nie. Dit was nie 'n humanisme wat hom in die eerste plek téén God opgestel het nie, maar wel vir die mens, meer in besonder vir 'n studie van die menswetenskappe. Die humaniste van die Renaissance het hulle met mening beywer vir 'n studie van die menswetenskappe soos grammatika, retorika, geskiedenis, digkuns en morele teologie; dus vir die studia humanitatis/humanioria (Kristeller, 1979:171). Hulle wou deur middel van hierdie studies die mensheid in sy wêreldlike en kerklike bestaan dien. Hierdie vorm van "menssentriese" denke was nie iets nuuts nie (vgl. 
Gen. 2!) en ook nie van ateïstiese snit nie. Dat daar hierin 'n (soms te) swaar aksent op die goedheid van die mens gelê is, kan natuurlik nie ontken word nie (Kristeller, 1979:21-32).

Wat hierbo gesê is, kan aan die hand van 'n aantal Renaissance-denkers geadstrueer word (Kristeller, 1979:169-181). Manetti prys die mens as gevolg van sy rede, sy kuns, sy natuur en sy kennis, maar hy ontken daarmee nie die werklikheid van die sonde en die noodsaaklikheid van verlossing nie. Pico della Mirandola skryf 'n (sogenaamde) Redevoering oor die waurdigheid van die mens waarin hy die mens as nòg hemels/onsterflik nòg aards/sterflik omskryf. Die mens kan deur ' $n$ keuse in een van hierdie rigtings ontwikkel en selfs met God verenig word. Die mens se waardigheid berus op sy vryheid van keuse en word gerealiseer as hy die beste keuse maak. Volgens Pomponazzi is die mens 'n dubbelsinnige wese, geplaas tussen die onsterflike/ewige en die sterflike/tydelike, en hy kan een van die twee aanneem. Morele deug hang nie van toekomstige hoop af nie, maar kan in die tyd gerealiseer word. Deug veroorsaak sy eie vergoeding en ondeug bring sy eie straf mee.

Ook die humanisme van Erasmus moet as Christelike humanisme getipeer word (of was dit dalk humanistiese of humane Christendom? - vgl. White, 1981:136-152). Wel gee sy opstel oor die vrye wil van die mens uitdrukking aan die Renaissance-gedagte dat die mens oor groot moontlikhede vir morele vooruitgang beskik en dat onkunde en onsin deur opvoeding oorwin kan word, maar tog steun hy in die ander werke op die verlossing deur Christus, beroep hy hom op die evangelie van Christus (in Grieks!), aksentueer hy die navolging van Christus, ook vir regeerders, en lê hy klem op innerlike vroomheid teenoor uitwendige seremonies. So staan hy vir spiritualiteit, simplisme, individualiteit en toleransie maar téén kerkisme, dogmatisme, skolastisisme, outoritarisme en formalisme.

Samevattend kan gevra word of die humanisme van die Renaissance die mens te hoog aangeslaan het, te veel van hom gedink het, en dit ten koste van God? Was daar sprake van 'n menssentriese denke ten koste van 'n teosentriese denke?

Moet ons met Jodocus van Lodenstein (1620-1677) saamstem dat "God alles en die mens niks" is (vgl. 1 Kor. 3:7)? Dit bring ons voor die teologiese vraagstelling te staan of daar vanuit 'n konkurrensiemotief, die mens of God (vgl. Van der Walt, 1956), of vanuit 'n verbondsperspektief, die mens en God, gedink moet word. Inderdaad is dit moontlik dat van die mens te vél gedink kan word (outonomisme), maar daar kan ook van die mens te mín gedink word (vgl. Barth, 1960:94 e.v.). Die gevolg is dat die mens verslaaf en mishandel kan word, dat daar teen hom gediskrimineer kan word, selfs deur Christene, en wel op so 'n wyse dat min van die menslike oorbly. Die Bybelse mensbeeld teken die mens ónder God maar bó die skepping, ja, as die kroon van die 
skepping, selfs as "byna goddelik" (Ps. 8:6). Wel word die mens ook in sy onmag en sonde uitgebeeld, maar dan ook in sy verlossing en heerlikheid. Nooit word ontken dat die mens, ook die gevalle mens, beeld van God is en dat hy God in hierdie wêreld moet representeer en reflekteer nie.

Aan die ander kant is die Bybelse Godsbeeld ook nie onmenslik nie. Die Bybel vertel ons van die "filantropie" van God, sy mensliewendheid (Tit. 3:4), ja van sy liefde vir die kosmos (Joh. 3:16). God hoef dus nie onmenslik te word om nog God te bly nie. Hy het sy Seun laat mens word juis om die wêreld te red.

Ongetwyfeld, die mens kán hom teen God verhef, hy kan hom van God losmaak, sons in die ateïstiese humanisme inderdaad gebeur het, maar hy kan ook as verbondsmens God dien daarin dat hy die heil en welsyn van sy medemens soek. Dikwels het daar in die geskiedenis van die mensdom sekulêre bewegings ontstaan as 'n protes teen 'n kerk wat in vormdiens vasgeval en van naasteliefde en medemenslikheid vergeet het. Die Christelike leer is wel nie humanisties nie maar tog voluit humaan.

Die aksentuering van twee sentrale teologiese temas soos verbond en koninknk het in ons eeu opnuut laat blyk in hoe 'n mate God Hom aan die mens verbind het, en die mens hom aan God, op weg na die groot toekoms wat Hy belowe het.

\subsection{Geloof en rede}

Oor die verhouding tussen geloof en rede - of die vraag na waarheid - is daar in die filosofie en teologie groot teorieë ontwerp en magtige sisteme gebou. Daar kan onder andere aan die volgende denksisteme gedink word (vgl. Van der Walt, 1981:91-99):

- fideisme (waar die geloof die rede uitskakel);

* dominisme (waar die geloof die rede domineer);

* dualisme (waar geloof en rede totaal apart van mekaar funksioneer - vgl. Kant);

* sciëntisme (waar die rede die geloof uitskakel);

- relasionisme (waar geloof en rede op mekaar betrek word as redelike geloof (Aquinas) of as gelowige rede (Augustinus)).

Vanselfsprekend is hierdie opsomming uiters ongenuanseerd en dus aanvegbaar. Die doel is egter slegs om binne die konteks van die tema'n aanduiding van moontlikhede te gee ten einde ' $n$ beter begrip van die Renaissance-denke hieroor te bekom.

Die opvallendste kenmerk van die Renaissance-denkers in hierdie verband is die dualistiese inslag (vgl. Kristeller, 1979:169-210). So (onder-)skei Pomponazzi geloof 
(dinge wat op sigself geloofwaardig is) en rede (dinge wat as waar bewys moet word). Geloof en teologie enersyds, en rede en filosofie andersyds, is soewerein in eie kring en dus is daar 'n pluraliteit van waarhede. Ficino ontwikkel die idee van universele waarheid en oordeel dat alle religie gebaseer is op die mens se fundamentele begeerte na God, met die Christendom as die mees volmaakte godsdiens.

Dit was egter Pico wat die konsep van universele waarheid die verste ontwikkel het. Alle filosofiese en teologiese tradisies vorm vir hom deel van die universele waarheid. Hy sê dat "this has been my reason for wishing to bring before the public the opinions not of a single school alone ... but rather of every school to the end that the light of truth ... through this comparison of several sects and this discussion of manifold philosophies might dawn more brightly on our minds". Verder oordeel hy dat "there has been nobody in the past, and there will be nobody after us, to whom truth has given itself to be understood in its entirety. Its immensity is too great for human capacity to be equal to it"(Kristeller, 1979:207). Hy stem dus saam met die skeptici dat dogmatisme verwerplik is, en met die eklektici dat in vryheid uit die verskillende denkers gekies moet word. Maar anders as die eklektici kies hy nie volgens gevoel nie, maar volgens 'n intuïtiewe sekerheid, en anders as die skeptici beklemtoon hy nie die ontoereikendheid wat alle menslike denke van die absolute waarheid skei nie, maar eerder die positiewe porsie wat dit uit die waarheid verkry.

Ook Cusanus (1401-1464) is van oordeel dat elke menslike leerstelling ' $n$ besondere uitdrukking van 'n universele waarheid is en dat deelwaarhede in die filosofie en teologie, selfs in die Islam, gevind kan word.

In Montaigne (1533-1592) ontmoet ons die skeptikus wat hom teen fanatisme en dogmatisme verset en insien dat die menslike rede begrens en relatief is. So 'n skeptisisme bring intellektuele vryheid met hom mee omdat dit bevry van gefikseerde leerstellings. Montaigne skei egter geloof en rede en oordeel dat die rede onmagtig is op die terrein van die metafisika, waar vaste waarhede geld wat op openbaring berus. Sy skeptisisme geld dus net die terrein van die rede en die filosofie en nie dié van die geloof en teologie nie.

Dit is duidelik dat die Renaissance-denkers die waarheidsvraag op 'n dualistiese wyse probeer benader het ('n skeiding van geloof en denke), met as uitvloeisel ' $n$ universele waarheid. In elk geval was daar'n sterk afkeer van alle dogmatisme.

Die opmerking van Fowler (1984:05) dat die hart van die Renaissance-denke geleë is in "an assertion of the autonomy of human reason, free of the dominating constraint, of a faith mediated by ecclesiastical authority" is net gedeeltelik juis, aangesien die outonomie van die menslike rede self onder kritiek was (deur die skeptici) en die rede 
ook dikwels binne die konteks van 'n dualisme tussen geloof en rede gefunksioneer het waar die rede nie oor geloofsake waarhede kon uitspreek nie.

Dit is egter teologies onhoudbaar om geloof en rede of totaal te skei ò totaal te vermeng. Die geloof is immers nie onredelik nie (Rom. 12:1), al was dit vir die Grieke 'n dwaasheid (1 Kor. 1:23), en die rede kan uiteindelik nie sonder geloof klaarkom nie. "Dit evangelie vraagt niet om een blinde gehoorzaamheid, noch om een sacrificium intellectus" (Berkouwer, 1972:61, vgl. 45). Die gevaar van fideïsme ('n blinde geloof) is net so groot as die gevaar van rasionalisme ('n blinde verstand). Ons denke moet deur God vernuut word om tussen goed en kwaad te kan onderskei (Rom. 12:2). Geloof en rede is twee lewensuitinge van die mens as geheel wat nòg geskei nòg vermeng mag word (vgl. Berkouwer, 1969:155-173, 1974:203-253; Van Ruler, 1972:9-29). Die Christelike geloof is nie rasionalisties nie, maar rasioneel. Dit lyk my verantwoord om sowel van 'n redelike geloof as van 'n gelowige rede te praat.

Die rasionalisme het natuurlik nie net negatiewe gevolge (gehad) nie. Vanweë die analiserende denkmetode het dit die fenomenale ontplooiing van die naturwetenskap met al sy verworwenhede bevorder. Andersyds het dit die nadelige uitwerking gehad van 'n verrasionalisering van belydenisuitsprake en 'n skematisering van die geloofslewe.

Die Waarheid is Een, naamlik Jesus Christus (Joh. 14:6), maar vanuit hierdie groot Waarheid straal kleiner waarhede soos die strale van die son elke lewensfaset binne. Hierdie kleiner waarhede lê nie pasklaar soos spoeldiamante net vir optel nie, maar moet soos goud deur menslike aktiwiteit gemyn en gemunt word. Hiermee word natuurlik nie ontken dat iemand wat nie die groot Waarheid het nie, iemand wat nie geloof in Jesus Christus het nie, nie ook kragtens God se algemene goedheid nog redelik en verstandig en wetenskaplik kan wees nie. Maar hiermee word wel gesê dat geloof en rede ten diepste afhanklik is van die lewende God wat Hom in die natuur en "nog duideliker en meer volkome" (Nederlandse Geloofsbelydenis, artikel 2) in die Skriftuur aan die mens kenbaar gemaak het.

\subsection{Kerk en wêreld}

Was die Renaissance-denke, in sy toewending na die wèreld, a-kerklik of selfs antikerklik? Berkhof (1955:129) meen dat die Renaissance nie bewustelik kerkvyandig was nie, maar Latourette (1938:339) oordeel dat die Renaissance "in some of its aspects obviously was non-Christian and even anti-Christian".

Daar moet egter onthou word dat die Middeleeuse Europese samelewing grotendeels 
deur kerkgesag gedomineer was, en eweneens die filosofie deur die teologie. Die Renaissance-denkers verset hulle nie in die eerste plek teen die kerk as sodanig nie, maar teen kerkisme, nie teen teologie nie maar teen teologiese diktatuur.

Interessant genoeg was die kerk nie noodwendig vyandig teenoor die Renaissance nie. Die kerk het trouens op talle maniere die humaniste en kunstenaars ondersteun en vergoed (Estep, 1986:28). Tog is die kerkgesag op talle maniere deur die Renaissance ondermyn.

Twee voorbeelde sal illustreer hoedat die kerk van daardie tyd in 'n totale oorskryding van sy magsbevor gdheid die wetenskaplikes probeer domineer het. In 1486 verbied pous Innocentius VIII Jat Pico sy 900 stellinge (oor pluralisme en waarheid) mag bespreek nadat 'n pouslike kommissie sommige daarvan hereties of twyfelagtig bevind het (Kristeller, 1979:174,206).

Meer bekend en opspraakwekkend is dat die Rooms-Katolieke Kerk in 1616 die teorie van Copernicus (van 'n dubbele aardbeweging: daagliks om sy as en jaarliks om die son) verbied het om hierdie teorie as waarheid te verkondig. In 1633 het Galilei, as verdagte ketter, hierdie teorieë afgesweer.

Hierdie voorbeelde illustreer duidelik hoedat die kerk, in 'n foutiewe verstaan van die Skrif, ook op 'n foutiewe wyse sy (morele!) gesag uitgeoefen het. Dit toon hoedat die kerk in die proses van verkerkliking van die wêreld inderdaad self verwèrelḋlik het, of, om dit anders te stel, in 'n poging om die sekulère te sakraliseer, is die sakrale gesekulariseer (vgl. Rienstra, 1961:50).

Hieruit blyk myns insiens baie duidelik watter gevare 'n verkerkliking van die wêreld en 'n daaruit voortvloeiende verwêreldliking van die kerk met hom meebring. Die kerk het sy bepaa'de roeping en taak, naamlik boodskapper van die evangelie van die koninkryk van Grid, met al die implikasies daaraan verbonde. As die kerk sy dienskneggestalte aflè en (wêreld-)heerser word, verloën hy Christus. Natuurlik moet die lig van die evangelie oor die volle lewe skyn, ook oor die wêreld, ja, ook oor die wetenskap. Dit word egter op 'n bepaalde wyse gedoen en vir 'n bepaalde doel: nié om die kerk te ve heerlik, ook nie om die wetenskap te domineer nie, maar sodat die wetenskap tot volle ontplooiing kan kom in diens van die koninkryk van God in hierdie wêreld. Die wêreld van die wetenskap is nie 'n waardevrye terrein wat sonder etiese beginsels kan funksioneer nie - dink maar net aan die ontwikkeling van kernwapens en watter ontsaglike morele vrae dit nie opgeroep het nie. Die kerk ondermyn egter sy opdrag indien hy meer oor sy opinie begaan is as oor die wil van God, meer op sy gesag staatmaak as op die gesag van die Woord van God, meer oor sy prestige bekommerd is as oor die eer van God. 
'n Tweede gevaar wat hier gesinjaleer moet word, is die biblisistiese en fundamentalistiese misbruik van die Bybel deur die kerk tydens die Renaissance. Die Bybel is nie bedoel as wetenskaplike handboek wat antwoorde op alle moontlike natuurkundige vrae verskaf nie, maar dit is 'n geloofsboek in die taal van die deursneemens geskryf met 'n baie spesifieke doel, naamlik om God in Christus te ken en in alles te dien.

\subsection{Optimisme en pessimisme}

Hierdie teologiese temas word afgesluit met 'n kort bespreking van 'n oënskynlik minderwaardige tema soos optimisme en pessimisme. Die Renaissance word volgens sommige immers gekenmerk deur 'n groot optimisme in vergelyking met die Middeleeuse pessimisme (Sassen, 1946:13). Nou is dit wel waar dat die motief van optimisme in die Renaissance voorgekom het. So het Facio byvoorbeeld, nogal deur aansporing van 'n monnik, 'n verhandeling geskryf oor die waardigheid (excellentia) van die mens, gerig teen pous Innocentius III se taamlike pessimistiese (misrabele) siening van die mens (Kristeller, 1979:170-172). Verskeie navorsers het egter daarop gewys dat die Renaissance-periode nie net optimisties was nie: "... the Renaissance was a splendid but not a happy age" (Kristeller, 1979:168, vgl. 306). 'n Mens dink in hierdie verband onwillekeurig aan Machiavelli (1469-1527), wat die mens as so korrup beskou het dat hy 'n baie streng regering nodig geag het.

Nuwe uitvindings, intellektuele vooruitgang en kulturele ontwaking gaan gewoonlik gepaard met 'n sterk gevoel van optimisme. So is die $20 \mathrm{e}$ eeu ingegaan met 'n oorweldigende gevoel van optimisme dat die mens uiteindelik daarin sou slaag om die lang verwagte utopia te bereik. In plaas daarvan het twee vernietigende wêreldoorloë die vooruitgangsgeloof verpletter en aanleiding gegee tot 'n pessimistiese ondergangstemming. Tans beleef ons die unieke situasie dat ons die eerste geslag mense is wat daartoe in staat is om deur middel van kernwapens alle lewe op aarde te vernietig.

Moet ons dan 'n pessimistiese lewenshouding inneem dat die verlede onherroeplik, die teenswoordige ontoereikend en die toekoms onseker is; dat die lewe 'n slingergang is tussen ontbering ('n onbereikbare doel) en verveling (wat bereik is) (Schopenhauer)?

'n Christelike benadering tot die toekoms is egter nog optimisties (daarvoor is die sonde te groot), ndg pessimisties (daarvoor is die genade te groot), maar wel spesimisties, dit wil sê, hoopvol (hoop = spes in Latyn). Christene hoop, vas en seker, op wat God belowe het, naamlik 'n nuwe hemel en 'n nuwe aarde waar alles reg is ( 2 Pet. 3:13). Ons sien nou reeds hier en daar klein tekens van die nuwe wèreld wat kom, maar dit bly grotendeels nog 'n geheim wat slegs in die geloof aanvaarbaar is. Maar die nuwe kom (Openb. 21:5), ja is reeds hier (2 Kor. 5:17), en wel op grond van die 
werk van Jesus Christus en die Gees van God (Rom. 8).

Wat sin gee aan die lewe, en wat die toekoms nader bring, is ten diepste nie afhanklik van menslike prestasies en ontwikkeling nie, hoe belangrik dit op sigself ook al mag wees, maar wel van God en sy heilshandelinge in Jesus Christus en sy Gees. Natuurlik moet al ons menslike arbeid gerig wees op die nuwe wêreld; dit is immers die rigting waarin ons lewe, maar dan altyd met die wete dat dit Gód is wat uiteindelik sy doel bereik, naamlik nuwe mense op 'n nuwe aarde onder 'n nuwe hemel - dwarsdeur die dood en oordeel heen.

\section{SLOT}

Die vraag word dikwels gestel, en uiteenlopend beantwoord, of die Reformasie 'n breuk met die Renaissance ingehou het; ' $n$ breuk wat dan eers weer in die $18 \mathrm{e}$ eeu deur die Aufklärung herstel is, en of dit 'n voortsetting van die Renaissance was. Berkhof (1955:131) sien slegs ' $n$ antitese tussen Renaissance en Reformasie: "De renaissance betekende de geboorte van de moderne mens, die geen gezag wil erkennen boven zijn eigen geestelijke vermogens. De reformatie betekende de wederoprichting van het gezag van Gods Woord. Deze twee levenshoudingen sluiten elkaar uit".

Dit skyn egter meer korrek te wees om te aanvaar dat daar sprake van sowel kontinuiteit as diskontinuïteit is. Dit sou eensydig wees om die Renaissance-denke slegs negatief te beoordeel. Aandag vir die mens, sy kennis, sy kuns, sy vryheid, is immers nie as sodanig verkeerd nie. Dit word verkeerd as dit los van en ten koste van God en sy koninkryk beklemtoon word.

Sonder twyfel vind die reformatoriese teologie vandag veel meer aansluiting by die Reformasie van die 16 e eeu as by die Renaissance van die $14 \mathrm{e}$ en $15 \mathrm{e}$ eeu, maar dit doen nie afbreuk aan die feit dat daar ook waardering kan wees vir die waardevolle aspekte van die Renaissance-denke nie. Die verlede mag nie kritiekloos nagevolg word nie, maar dit mag ook nie onnadenkend geïgnoreer word nie. Die gevaar van sintese-denke moet vermy word, maar 'n verabsoluteerde antitese-denke bring ook nie welsyn nie. Antitese moet daar wees, maar dan teen die sónde en nie teen die natuur en skepping van God nie. Uiteindelik moet "elke gedagte" gevange geneem word tot gehoorsaamheid aan Christus (2 Kor. 10:5). 


\section{BIBLIOGRAFIE}

BARTH, K. 1960. Die Kirchliche Dogmalik IV 1: Dic Lehre von der Versöhnung. Zürich : EVZVerlag.

BERKHOF, H. 1955. Geschiedenis der kerk. Ge druk. Nijkerk : Callenbach.

BERKOUWER, G.C. 1969. Verontrusting en Verantwoordelijkheid. Kampen : Kok.

BERKOUWER, G.C. 1972. De Kerk II: Apostoliciteit en heiligheid. Kampen : Kok

BERKOUWER, G.C. 1974. Een halve ecuw theologic: Moticven en stromingen van 1920 tot heden. Kampen : Kok.

BURCKHARDT, J. 1935. The civilization of the Renaissance in Italy. Translated by S.G.C. Middlemore. New York: Albert \& Charles Boni (oorspr. 1860).

BURDACH, K. 1926. Reformation und Renaissance. Halk: Niemcycr.

ESTEP, W.R. 1986. Renaissancc and reformation. Grand Rapids : Ecrdmans.

FOWLER, S. 1984. Faith and reason in the period of the Reformation. (In Van der Walt, BJ. ed. Our Reformational Tradition: A rich heritage and lasting vocation. Potchefstroom : PU CHE/IRS. p. 61-85.)

HYMA, A. 1951. Renaissance to Reformation. Grand Rapids : Ecrdmans.

KLAPWIJK, J. 1986. Orientatic in de nicuwe filosofic. Assen : Van Gorcum.

KRISTELLER, P.O., RANDALL, H.R. Jr. \& CASSIRER, E. eds. 1956. The Renaissance philosophy of man: Gencral Introduction. Chicago : University of Chicago Press.

KRISTELLER, P.O. 1961. Renaissance thought: The classic, scholastic and humanistic strains. New York : Harper and Brother.

KRISTELLER, P.O. 1964. Eight philosophers of the renaissance. Stanford : Stanford Univ. Press.

KRISTELLER, P.O. 1979. Renaissance thought and its sources. (Ediled by M. Mooney.) York : Columbia University Press.

LATOURETTE, K.S. 1938. A history of the expansion of Christianily: The thousand years of uncertainty: AD 500 - AD 1500. Ncw York: Harper \& Brothers.

NAUERT, C.G. 1981. The age of Renaissance and Reformation. Washington : University Press.

OBERMAN, H.O. 1967a. Forerunners of the Reformation: The shape of late medieval thought. London : Lutherworth Press.

OBERMAN, H.O. 1\%7h. The harvest of medieval thought. Girand Rapids: Eerdmans.

OBERMAN, H.O. 1974. The shape of late medieval thought: the birthpangs of the modern era. (In Trinkhaus, C. \& Oberman, H. eds. The pursuit of holiness in Latc Medieval and Renaissance Religion. Leiden : Brill.)

OBERMAN, H.O. \& BRADY jr., T.A. 1975. Itinerarium Italicum: The profile of the Italian Renaissance in the mirror of its European transformations. Leiden : Brill.

RIENSTRA, M.H. 1981. The Religious Problem of the Renaissance. (In Van der Goot, H. ed. Life is Religion: Essays in Honor of H. Evan Runner. St. Catharines, Ontario : Paidcia Press, p. 45(0).)

SASSEN, F. 1946. Geschiedenis van de nicuwere wijsbegecrte tol Kant. 2e druk. Antwerpen : NV Standaard.

STUMPF, S.E. 1982. Socrates to Sartre: A history of philosophy. New York : Mc Graw-fill.

TRINKHAUS, C. 1976. Humanism, Religion, Socicty: Concepts and Motivations of Some Recent Studics. Renaissance Quancrly, 29: 676-713.

VAN DER WALT, B.J. 1979. Die denkdekor van dic Reformasic: Met spesiale veruysing na Calvyn. Potchcfstroom : PU vir CHO.

VAN DER WALT, B.J. 1981. Van Athene na Genève: Kort oorsig oor dic geskiedenis van die Wysbegeerte vanaf dic Gricke tot die Reformasic. Potchefstroom : Pro Rege.

VAN DER WALT, B.J. 1982. Renaissance and Reformation: Contemporaries but not allics. ( $n$ Van der Walt, B.J. Calvinus Reformator: His contribution to theology, church and socicty. Potchcfstrom : PU vir CHO, p. 85-92.) 
VAN DER WALT, SJ. 1956. Die mens of God?: Perspekticwe van moderne humanisme. Potgietersrus : Môrester.

VAN GELDER, H.A.E. 1961. The two reformations in the 16th century: A study of the religious aspects and consequences of Renaissance and Humanism. Den Haag: Nijhoff.

VAN RULER, A.A. 1972. Thcologisch Werk Decl IV. Nijkerk : Callenbach.

WHITE, R.E.O. 1981. The Changing Continuity of Christian Ethics Vol 2: The Insights of History. Exeter : Paternoster. 